\title{
Effect of Nitrogen Content on Hot Deformation Behavior and Grain Growth in Nuclear Grade 316LN Stainless Steel
}

\author{
Ming-wei Guo, ${ }^{1,2}$ Zhen-hua Wang, ${ }^{1,3}$ Ze-an Zhou, ${ }^{1}$ Shu-hua Sun, ${ }^{1}$ and Wan-tang Fu ${ }^{1}$ \\ ${ }^{1}$ State Key Laboratory of Metastable Materials Science and Technology, Yanshan University, Qinhuangdao 066004, China \\ ${ }^{2}$ China First Heavy Industries, Qiqihar 161042, China \\ ${ }^{3}$ Key Laboratory of Advanced Forging \& Stamping Technology and Science Yanshan University, Ministry of Education of China, \\ Qinhuangdao 066004, China
}

Correspondence should be addressed to Wan-tang Fu; wtfu@ysu.edu.cn

Received 1 July 2015; Accepted 11 August 2015

Academic Editor: Jörg M. K. Wiezorek

Copyright (C) 2015 Ming-wei Guo et al. This is an open access article distributed under the Creative Commons Attribution License, which permits unrestricted use, distribution, and reproduction in any medium, provided the original work is properly cited.

\begin{abstract}
$316 \mathrm{LN}$ stainless steel with $0.08 \% \mathrm{~N}(08 \mathrm{~N})$ and $0.17 \% \mathrm{~N}(17 \mathrm{~N})$ was compressed at $1073-1473 \mathrm{~K}$ and $0.001-10 \mathrm{~s}^{-1}$. The hot deformation behavior was investigated using stress-strain curve analysis, processing maps, and so forth. The microstructure was analyzed through electron backscatter diffraction analysis. Under most conditions, the deformation resistance of $17 \mathrm{~N}$ was higher than that of $08 \mathrm{~N}$. This difference became more pronounced at lower temperatures. The strain rate sensitivity increased with increasing temperature for types of steel. In addition, the higher the $\mathrm{N}$ content, the higher the strain rate sensitivity. Hot deformation activation energy increased from $487 \mathrm{~kJ} / \mathrm{mol}$ to $549 \mathrm{~kJ} / \mathrm{mol}$ as $\mathrm{N}$ concentration was increased from $0.08 \%$ to $0.17 \%$. The critical strain for initiation of dynamic recrystallization was lowered with increasing $\mathrm{N}$ content. In the processing maps, both power dissipation ratio and unstable region increased with increasing $\mathrm{N}$ concentration. In terms of microstructure evolution, $\mathrm{N}$ promoted dynamic recrystallization kinetic and decreased dynamic recrystallization grain size. The grain growth rate was lower in $17 \mathrm{~N}$ than in $08 \mathrm{~N}$ during heat treatment. Finally, it was found that $\mathrm{N}$ favored twin boundary formation.
\end{abstract}

\section{Introduction}

316LN stainless steel containing a low $\mathrm{C}$ content has good stress corrosion resistance. The addition of $\mathrm{N}$ induces excellent high temperature mechanical properties. Therefore, 316LN stainless steel is widely used in the energy industries and is one of the candidate structural materials for fast breeder reactors $[1,2]$.

$\mathrm{N}$ content has significant influences on the microstructure and properties of $316 \mathrm{LN}$ stainless steel. In terms of chemical properties, critical pitting potential increases with the increase in nitrogen content from $0.07 \%$ to $0.22 \%$ in type 316LN stainless steel in a mill-annealed condition [3]. Nitrogen alloying enriched the chromium within the passive film [4]. In terms of mechanical properties, the steady state creep rate decreased significantly with increasing nitrogen content $[5,6]$, and a similar phenomenon was also found in impression creep tests $[7,8]$. When the $\mathrm{N}$ content was no more than
$0.14 \%, 316 \mathrm{LN}$ stainless steel with higher $\mathrm{N}$ content showed better crack growth resistance at ambient [9] and high temperature [10]. In terms of microstructure evolution, the temperature of the onset of dynamic strain aging in $316 \mathrm{LN}$ steel with $0.22 \% \mathrm{~N}$ is $773 \mathrm{~K}$, while that in $316 \mathrm{LN}$ with $0.078 \% \mathrm{~N}$ is found to be $673 \mathrm{~K}$ [11]. The dislocation structure changed from cellular to planar with increasing $\mathrm{N}$ content from $0.04 \%$ to $0.1 \%$ during low cycle fatigue tests at $873 \mathrm{~K}$ [12].

A few of the reports concerned the hot working characteristics. Grain size was reduced from $100 \mu \mathrm{m}$ to $47 \mu \mathrm{m}$ when the nitrogen concentration was increased from $0.04 \%$ to $0.10 \%$ after hot rolling and heat treatment at $1373 \mathrm{~K}$ [12]. Tendo et al. [13] found that, in the $\mathrm{CrNi}$ steel with similar chemical composition with 316LN stainless steel, the flow resistance is higher in $0.25 \% \mathrm{~N}$ containing steel than that in $0.05 \%$ steel. It can be inferred that $\mathrm{N}$ content could affect the hot working behavior of 316LN stainless steel. The deformation parameter in $[12,13]$ is single and the effect of $\mathrm{N}$ content on 
TABLE 1: Compositions of 316LN stainless steel (wt.\%).

\begin{tabular}{cccccccccc}
\hline & $\mathrm{N}$ & $\mathrm{C}$ & $\mathrm{Cr}$ & $\mathrm{Ni}$ & $\mathrm{Mo}$ & $\mathrm{Si}$ & $\mathrm{Mn}$ & $\mathrm{P}$ & $\mathrm{S}$ \\
\hline $08 \mathrm{~N}$ & 0.08 & 0.017 & 16.93 & 13.11 & 2.70 & 0.61 & 1.41 & 0.010 & 0.0033 \\
$17 \mathrm{~N}$ & 0.17 & 0.015 & 17.26 & 13.28 & 2.81 & 0.67 & 1.46 & 0.011 & 0.0039 \\
\hline
\end{tabular}

these properties may not be monotonic, as observed in the investigation of creep [6] and fatigue properties [9] of 316LN stainless steel with notch specimens.

The hot deformation behaviors of high nitrogen $(\mathrm{N}$ $>0.5 \%$ ) CrMn austenitic stainless steel with different $\mathrm{N}$ contents were investigated extensively [14-16]. However, the effect of $\mathrm{N}$ content on the hot working characteristics of $\mathrm{CrNi}$ austenitic stainless steel $(\mathrm{N}<\sim 0.3 \%)$ has not been addressed systematically. Therefore, the hot working characteristics and grain growth behaviors of $316 \mathrm{LN}$ steels with $0.08 \% \mathrm{~N}$ and $0.17 \% \mathrm{~N}$ were investigated in the temperature range of $1073-$ $1473 \mathrm{~K}$ and strain rate range of $0.001-10 \mathrm{~s}^{-1}$. The aim of this study is to reveal the $\mathrm{N}$ content effect and to optimize the chemical composition.

\section{Experimental Materials and Procedure}

316LN stainless steels were melted in an arc furnace and then refined and cast in a vacuum environment. The principal difference between these two alloys is the percentage of nitrogen, as shown in the chemical compositions listed in Table 1.

After forging, slabs with dimensions of $40 \times 40 \mathrm{~mm}$ were cut and rolled at $1273 \mathrm{~K}$. The cumulative deformation was approximately 1 . The rolled slabs were held at $1373 \mathrm{~K}$ for $10-30 \mathrm{~min}$, resulting in a homogenized microstructure with average grain size of $80 \mu \mathrm{m}$ for $08 \mathrm{~N}$ and $17 \mathrm{~N}$. Hot compression specimens $(\Phi 10 \times 16 \mathrm{~mm})$ were machined parallel to the rolling direction. Hot compression tests were conducted on a Gleeble-3500 thermal/mechanical simulator. Graphite foil was used as a lubricant between the specimen and compression dies. Specimens were preheated at a rate of $10 \mathrm{Ks}^{-1}$ to $1073-1473 \mathrm{~K}$. Thereafter, compression tests were performed at $0.001,0.01,0.1,1$, and $10 \mathrm{~s}^{-1}$. Specimens were deformed to a strain of 0.8 and then quenched immediately in water. To investigate the grain growth behavior, some rolled slabs were cut and then held at $1473 \mathrm{~K}$ for 5-300 min.

Deformed specimens were sectioned parallel to the direction of compression. The observation area was situated in the center of the specimen. Heat treated specimens were also cut along the center. The sectioned specimens were ground using 100-1200 grit SiC paper followed by polishing with 3-, 1-, and $0.5-\mu \mathrm{m}$ oil-based diamond slurries. Final electrical polishing was conducted in a solution consisting of $20 \mathrm{~mL} \mathrm{HNO}_{3}$ and $80 \mathrm{~mL}$ methanol at $20 \mathrm{~V}$ and $-30^{\circ} \mathrm{C}$. The microstructures were observed using electron backscatter diffraction (EBSD) analysis with TSL-OIM-Analysis software. The spatial resolution was $1-3 \mu \mathrm{m}$ and the misorientation detection limit was $1^{\circ}$. The crystal orientation maps displayed high-angle grain boundaries (misorientation $\geq 15^{\circ}$, shown as black lines) and twin boundaries (shown as white lines). The grain boundary profile and differences in crystallographic orientation of the specimens after the hot compression or the heat treatment tests were plotted as inverse pole figure maps.

\section{Experimental Results and Analysis}

3.1. Flow Behaviors. The flow curves of 316LN steels with different N content obtained at $0.001-10 \mathrm{~s}^{-1}$ and $1073-1473 \mathrm{~K}$ are shown in Figure 1. Under most conditions, the flow stress of $17 \mathrm{~N}$ is higher than that of $08 \mathrm{~N}$. This difference becomes more pronounced at lower temperatures. At $1473 \mathrm{~K}$, their flow curves almost coincide with each other.

The character of dynamic recrystallization (DRX) is more obvious for $17 \mathrm{~N}$; that is, stress rises to a maximum at a peak strain and then diminishes to a value intermediate between the yield stress and the peak stress (Figures 1(a) and 1(b)). This may be induced by the lower stacking fault energy of $17 \mathrm{~N}$, which favors DRX. In Figure $1(\mathrm{a}), 08 \mathrm{~N}$ shows a continuous hardening behavior at $0.001 \mathrm{~s}^{-1}$. This phenomenon disappears at higher strain rate conditions, which may be caused by flow instability [16] and/or deformation heat [17].

According to [18], the relationship between strain rate sensitivity and strain for $08 \mathrm{~N}$ and $17 \mathrm{~N}$ in the temperature range $1073-1473 \mathrm{~K}$ can be obtained through further processing of the strain-stress data, as shown in Figure 2. The strain rate sensitivity is increased with increasing temperature for both $08 \mathrm{~N}$ and $17 \mathrm{~N}$. It is worth noting that the higher the $\mathrm{N}$ content, the higher the strain rate sensitivity.

3.2. Hot Deformation Equation. The relationship between the peak stress, the deformation temperature, and the strain rate (i.e., hot deformation equation) can be described as the classical hyperbolic sine function (1) when the metal is deformed at elevated temperature. Consider the following:

$$
\dot{\varepsilon}=A[\sinh (\alpha \sigma)]^{n} \exp \left(\frac{-Q}{R T}\right)
$$

where $A$ and $\alpha$ are material constants, which are independent of deformation temperature, $n$ is the stress exponent, $Q$ is a hot deformation activation energy, $R$ is the gas constant, $T$ is the absolute temperature, and $\sigma$ is the static stress, or peak stress, or the stress for a given strain. In this work, the peak stress is taken. According to [19], through linear regression, average values of every parameter can be obtained, as shown in Figures 3 and 4 . The hot deformation equation of $08 \mathrm{~N}$ and $17 \mathrm{~N}$ can be expressed as (2) and (3), respectively. Consider the following:

$$
\begin{aligned}
& \dot{\varepsilon}=1.63 \times 10^{19}[\sinh (0.00556 \sigma)]^{6.76} \exp \left(\frac{-487000}{R T}\right) \\
& \dot{\varepsilon}=6.41 \times 10^{21}[\sinh (0.00521 \sigma)]^{7.06} \exp \left(\frac{-549000}{R T}\right) .
\end{aligned}
$$

Obviously, the $Q$ of $316 \mathrm{LN}$ stainless steel increases from $487 \mathrm{~kJ} / \mathrm{mol}$ to $549 \mathrm{~kJ} / \mathrm{mol}$ as $\mathrm{N}$ concentration is increased from $0.08 \%$ to $0.17 \%$.

The Zener-Hollomon parameter ( $Z$ parameter), known as the temperature modified strain rate, is widely used to 


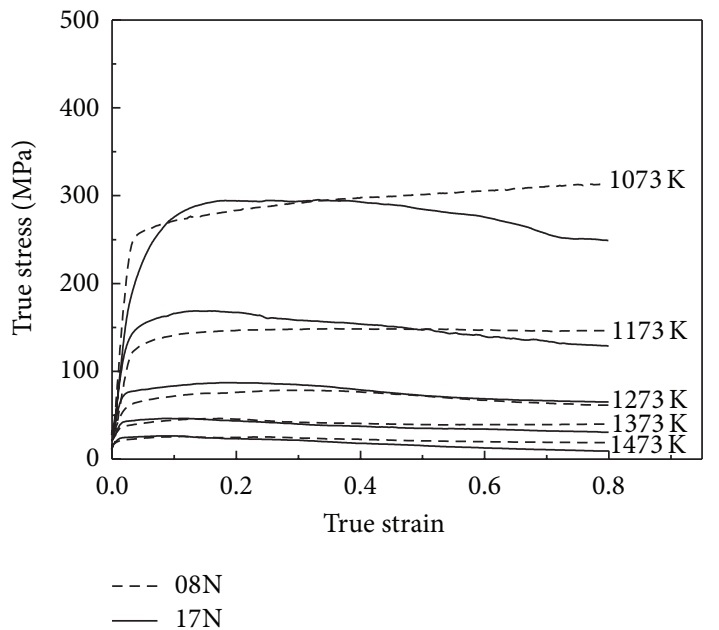

(a)

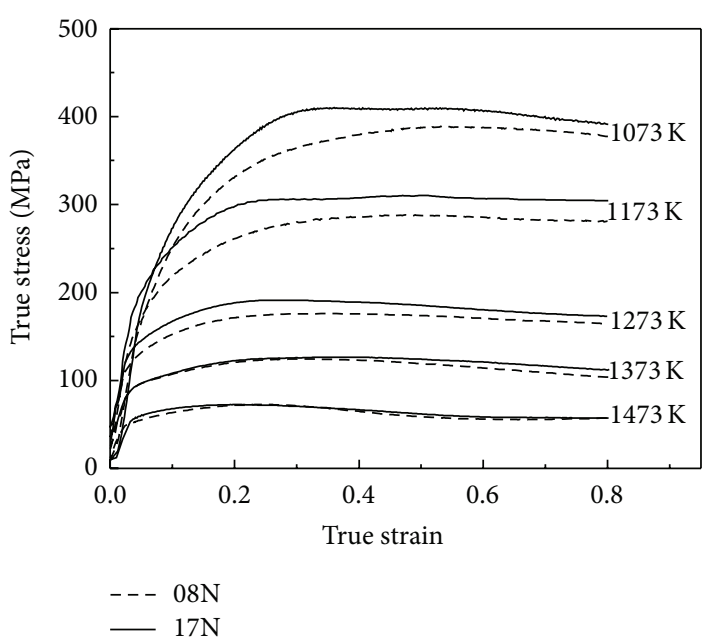

(c)

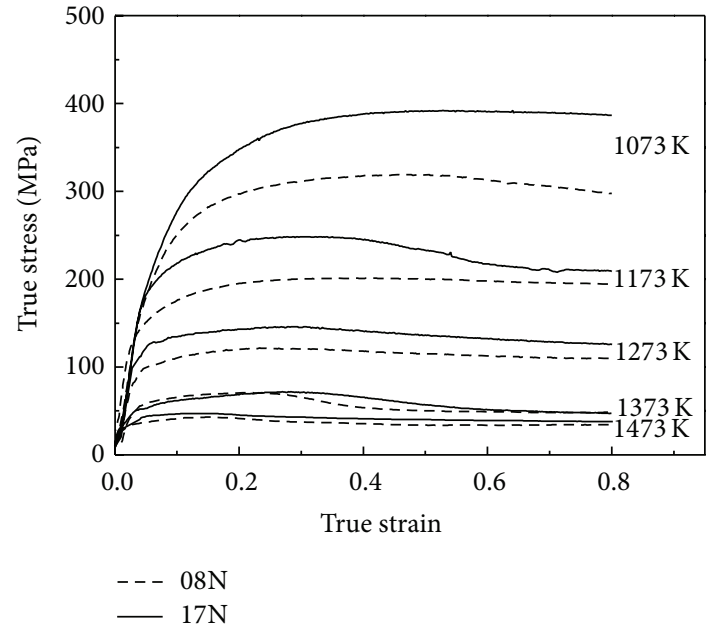

(b)

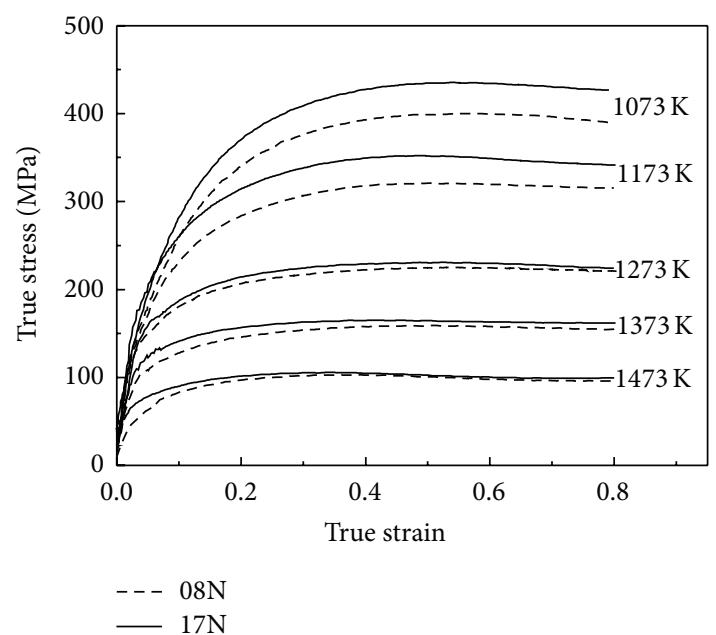

(d)

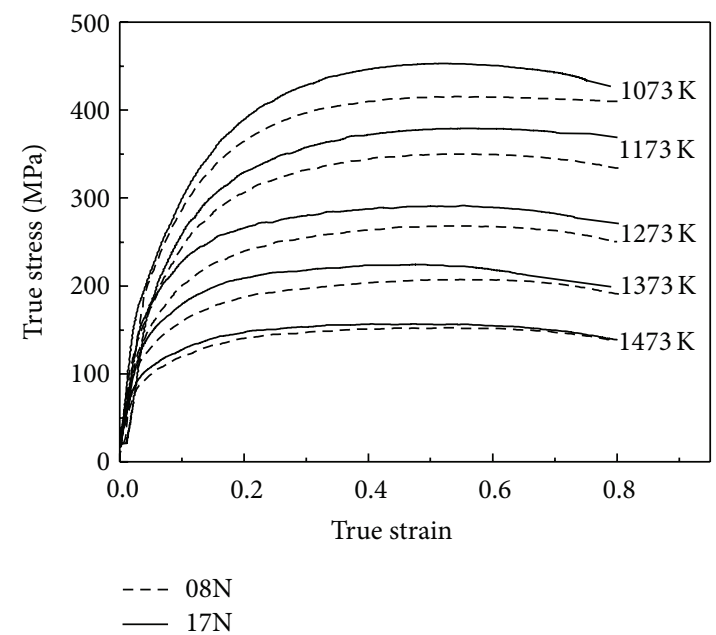

(e)

FIGURE 1: Flow curves of 316LN steel with different $\mathrm{N}$ content deformed at different strain rates: (a) $0.001 \mathrm{~s}^{-1}$, (b) $0.01 \mathrm{~s}^{-1}$, (c) $0.1 \mathrm{~s}^{-1}$, (d) $1 \mathrm{~s}^{-1}$, and $(\mathrm{e}) 10 \mathrm{~s}^{-1}$. 


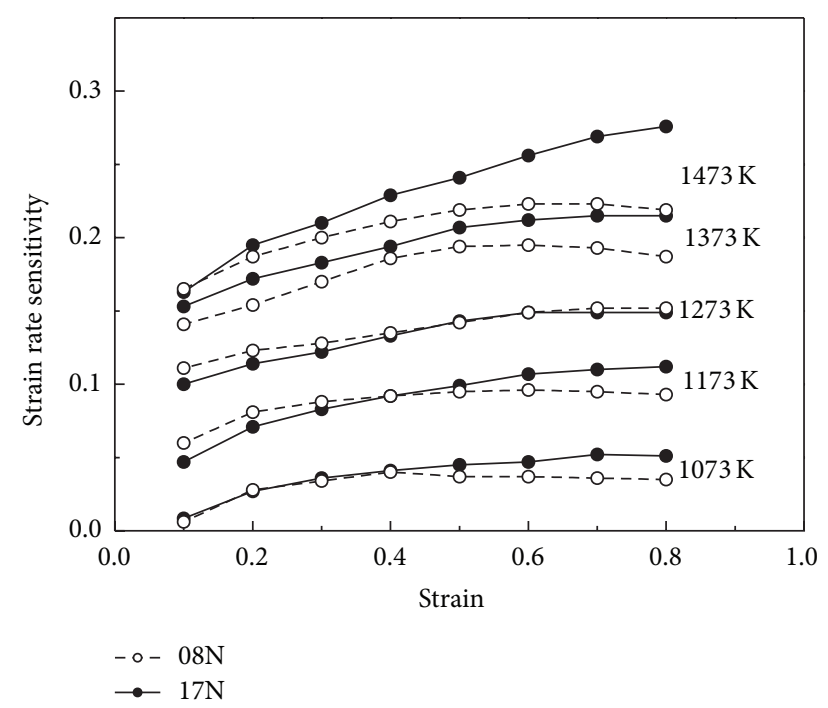

FIGURE 2: Strain rate sensitivity of $08 \mathrm{~N}$ and $17 \mathrm{~N}$.

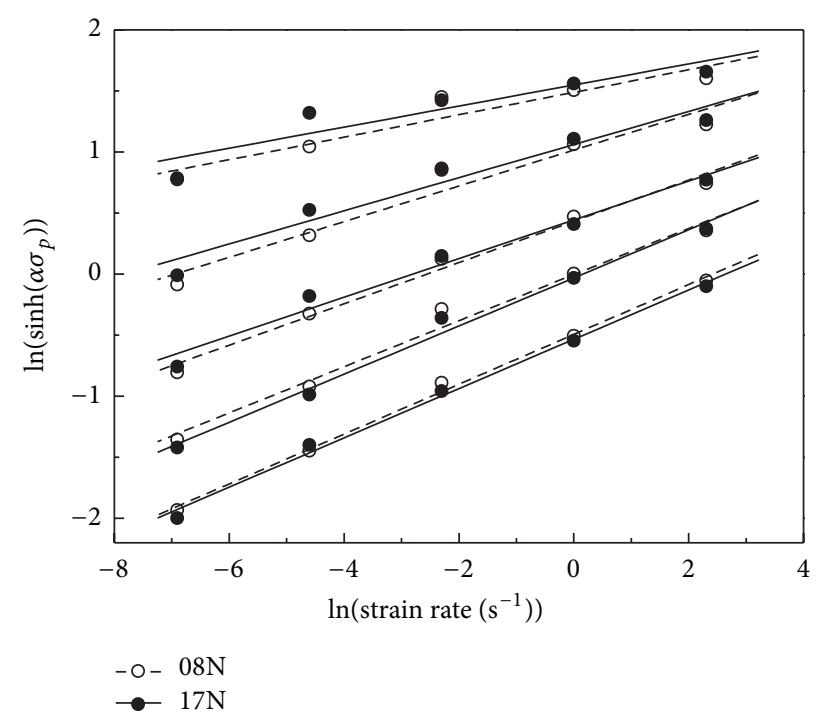

FIGURE 3: Relationship curves of peak stress with strain rate and deformation temperature for $316 \mathrm{LN}$ stainless steels: $\ln [\sinh (\alpha \sigma)]$ and $\ln \dot{\varepsilon}$.

characterize the combined effect of strain rate and temperature on the deformation process, as shown in the following:

$$
Z=\dot{\varepsilon} \exp \left(\frac{Q}{R T}\right)
$$

Substituting the $Q$ values into (4), we obtain

$$
\begin{aligned}
& Z=\dot{\varepsilon} \exp \left(\frac{487000}{R T}\right) \\
& Z=\dot{\varepsilon} \exp \left(\frac{549000}{R T}\right) .
\end{aligned}
$$

3.3. Critical Strain for Initiation of DRX. Poliak et al. [20, 21] found that the initiation of DRX is associated with the point of inflection in the curve of strain hardening rate $\theta$ versus flow stress $\sigma$. The simplest equation, which has an inflection point,

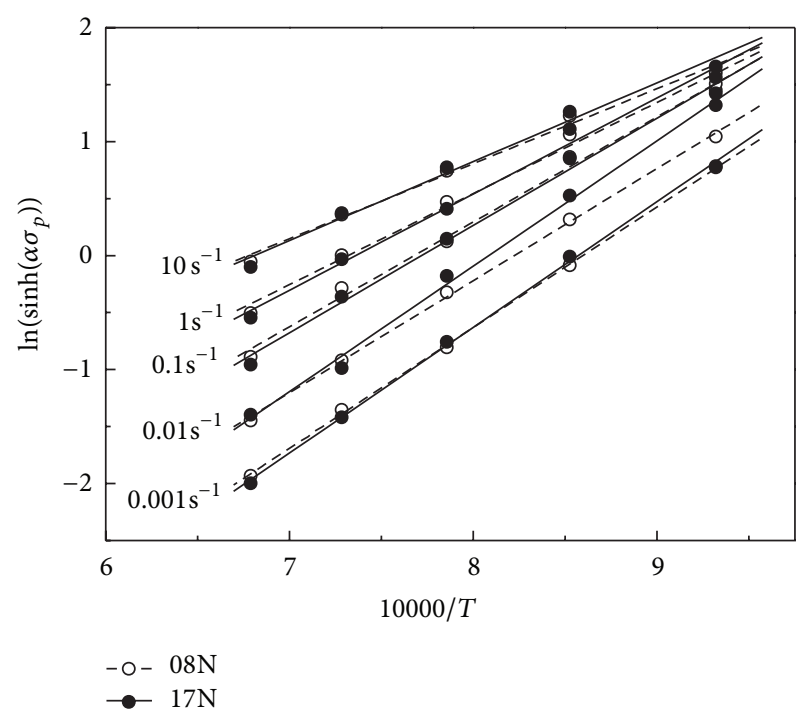

FIgURE 4: Relationship curves of peak stress with strain rate and deformation temperature for 316LN stainless steels: $\ln [\sinh (\alpha \sigma)]$ and $1 / T \times 10^{4}$.

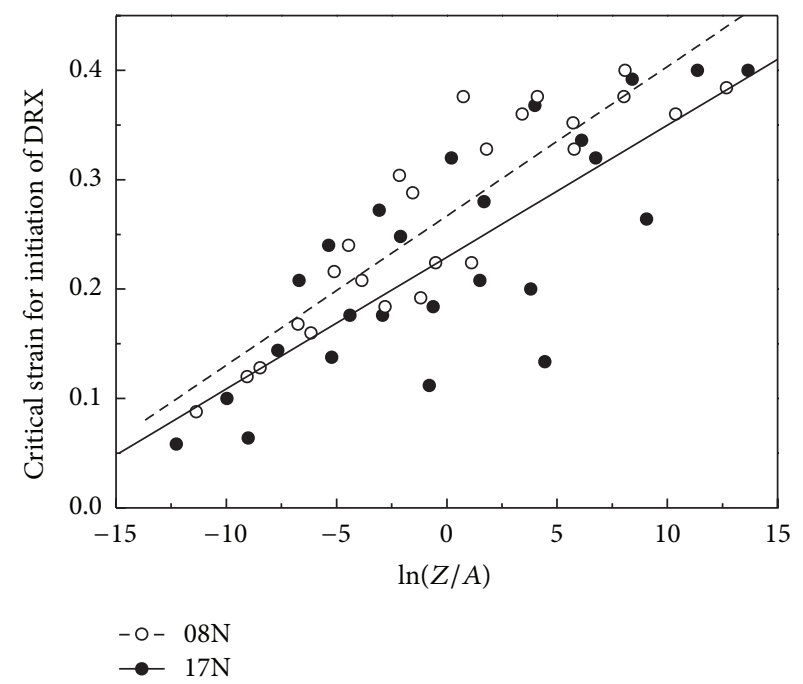

FIGURE 5: Dependence of the critical strain for the initiation of DRX on the $Z$ parameter in the tested steel.

fits the experimental $\theta-\sigma$ data from zero until the peak stress is

$$
\theta=A \sigma^{3}+B \sigma^{2}+C \sigma+D
$$

where $\theta=d \sigma / d \varepsilon$ and $A, B, C$, and $D$ are constants for a given set of deformation conditions. On taking partial derivatives of (6), then

$$
\frac{d \theta}{d \sigma}=3 A \sigma^{2}+2 B \sigma+C
$$

The minimum point of this second-order equation corresponds to the critical stress; that is, $\sigma_{c}=-B / 3 A$. Based on $\sigma_{c}$, the critical strain $\left(\varepsilon_{c}\right)$ for initiation of DRX can be read from the strain-stress data. The dependence of $\varepsilon_{c}$ on $\ln (Z)$ is shown in Figure 5. There is a linear relationship between $\varepsilon_{c}$ and $\ln Z$ :

$$
\varepsilon_{c}=0.121 \ln \left(\frac{Z}{A}\right)+0.229
$$




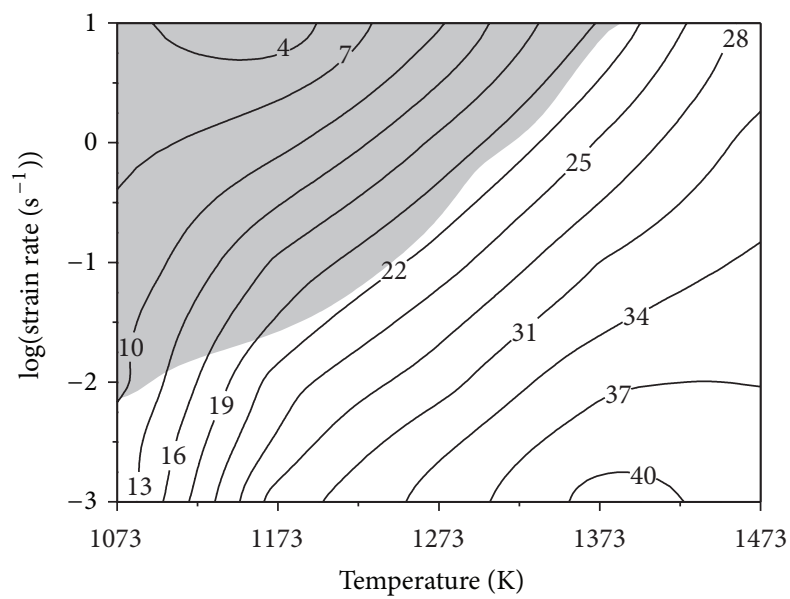

(a)

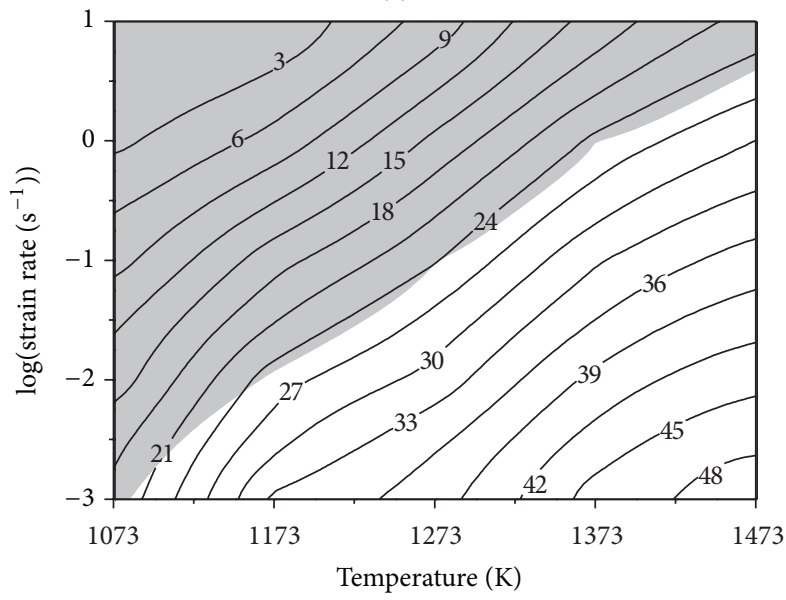

(c)

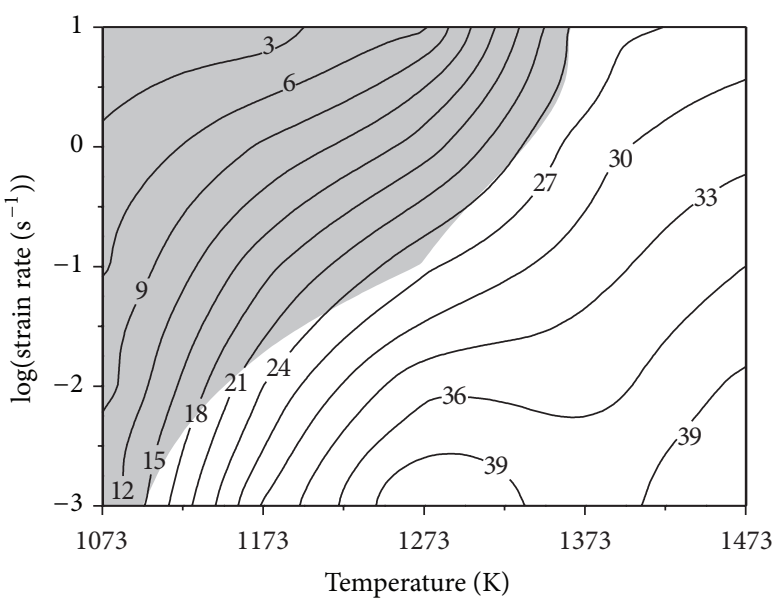

(b)

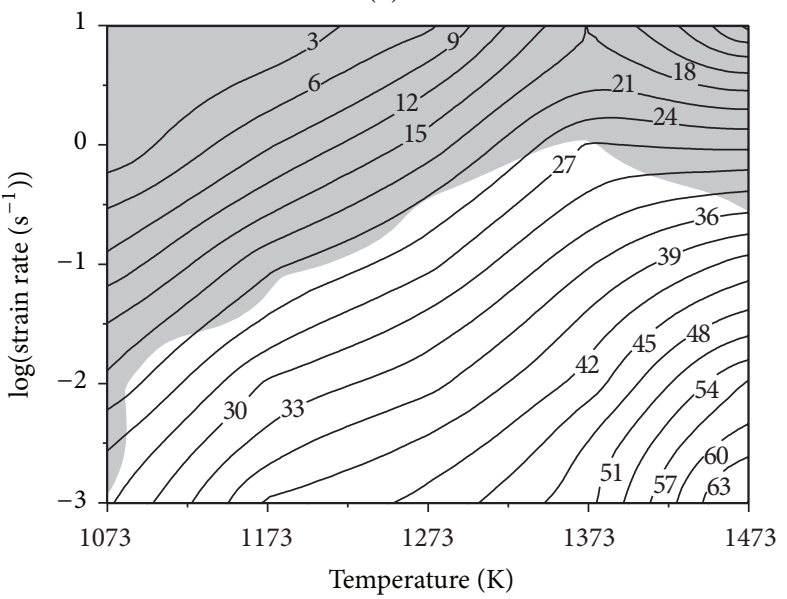

(d)

FIgURE 6: Processing maps obtained on 316LN steels at different strains. (a) $08 \mathrm{~N}, 0.4$; (b) $08 \mathrm{~N}, 0.8$; (c) $17 \mathrm{~N}, 0.4 ;$ (d) $17 \mathrm{~N}, 0.8$.

$$
\varepsilon_{c}=0.136 \ln \left(\frac{Z}{A}\right)+0.266
$$

It can be seen that the critical strain for initiation of DRX was lowered with increasing $\mathrm{N}$ content.

3.4. Processing Maps. The theoretical basis and methods for hot processing maps to be established have been described in detail earlier by Prasad and Sasidhara [22]. A workpiece deformed under hot working conditions can be considered to be a power dissipator. The strain rate sensitivity index $m$ for determining the distribution between the system power dissipation caused by viscous-plastic deformation and that caused by structural changes, wherein the ratio of power dissipation due to structural changes in the deformation process is denoted by $\eta$ (known as power dissipation ratio), indicates how efficiently the material dissipates energy under microstructural changes. It can be defined as

$$
\eta=\frac{2 m}{m+1}
$$

This parameter $\eta$ varies with deformation temperature and strain rate. The power dissipation map can be obtained based on the values of $\eta$ under different conditions. The following shows the flow instability criteria:

$$
\xi=\left\{\frac{\partial \ln [m /(m+1)]}{\partial \ln \dot{\varepsilon}}\right\}+m<0 .
$$

Flow instabilities are predicted to occur when $\xi$ is negative. The instability map may be superimposed on the power dissipation map to obtain a processing map. Processing maps for the tested steels, developed at different strains, are shown in Figure 6.

Contour numbers represent the percent efficiency of dissipation and the shaded region corresponds to flow instability in Figure 6. The power dissipation ratios of $08 \mathrm{~N}$ and $17 \mathrm{~N}$ both increase with increasing temperature and decreasing strain rate (lower $Z$ condition). Flow instability regions are localized at higher $Z$ conditions. For $08 \mathrm{~N}$, the power dissipation ratio has not changed significantly with strain. However, the dissipation of $17 \mathrm{~N}$ increases with increasing strain and is higher than that of $08 \mathrm{~N}$ at a given $Z$ condition. In addition, the flow instability region is larger in $17 \mathrm{~N}$ than that in $08 \mathrm{~N}$.

The higher power dissipation ratio indicates that $17 \mathrm{~N}$ favors DRX. This is consistent with the shapes of their flow 


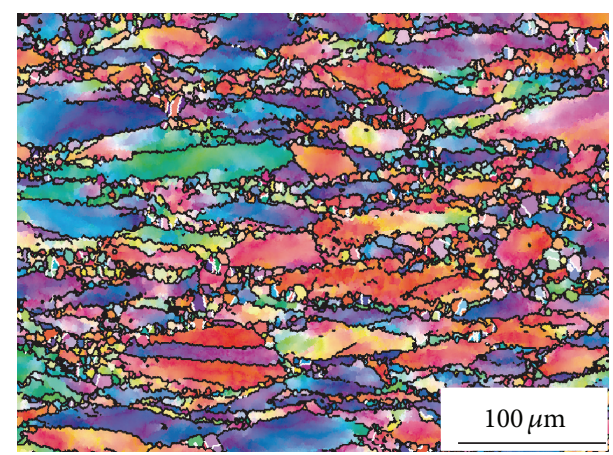

(a)

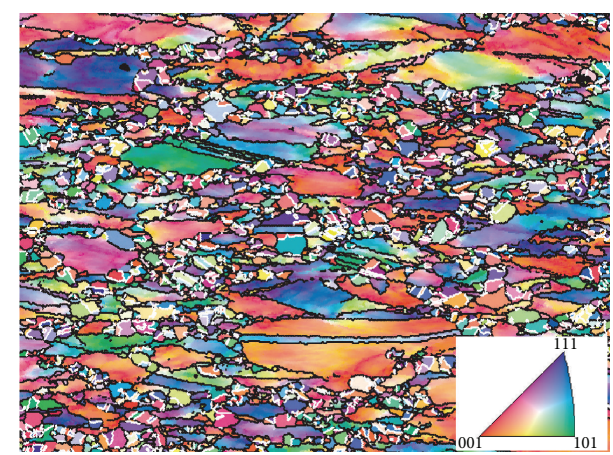

(b)

Figure 7: Microstructure of $316 \mathrm{LN}$ steels with different $\mathrm{N}$ content deformed at $1273 \mathrm{~K}$ and $0.1 \mathrm{~s}^{-1}$ : (a) $08 \mathrm{~N}$; (b) $17 \mathrm{~N}$ (the vertical direction is compression direction).

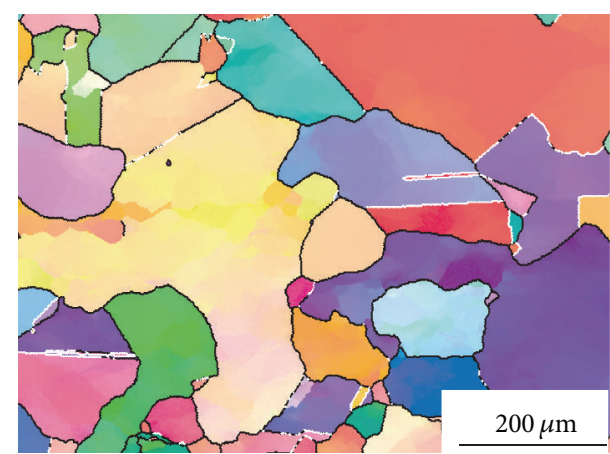

(a)

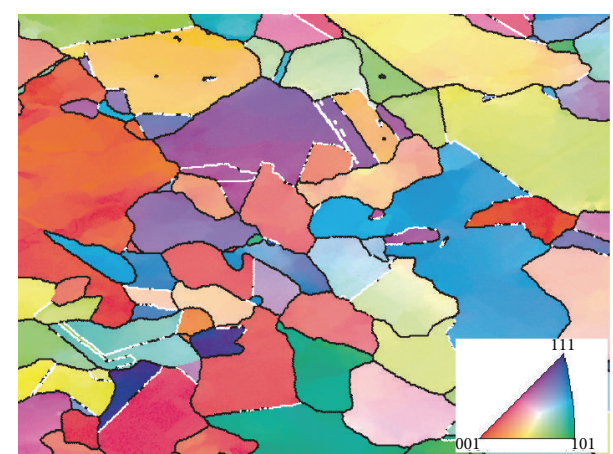

(b)

Figure 8: Microstructure of 316LN steels with different N contents deformed at $1473 \mathrm{~K}$ and $0.001 \mathrm{~s}^{-1}$ : (a) $08 \mathrm{~N}$ (b) $17 \mathrm{~N}$.

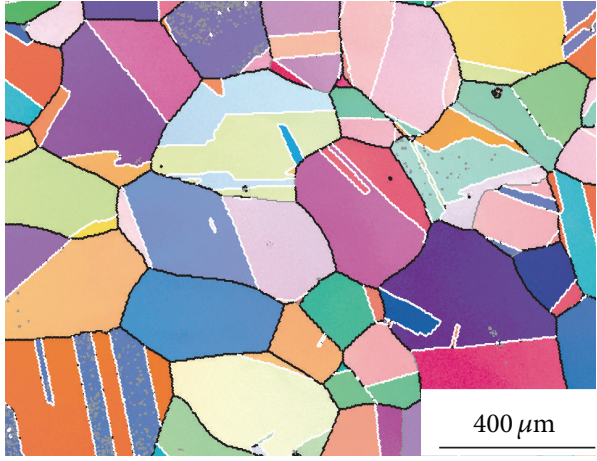

(a)

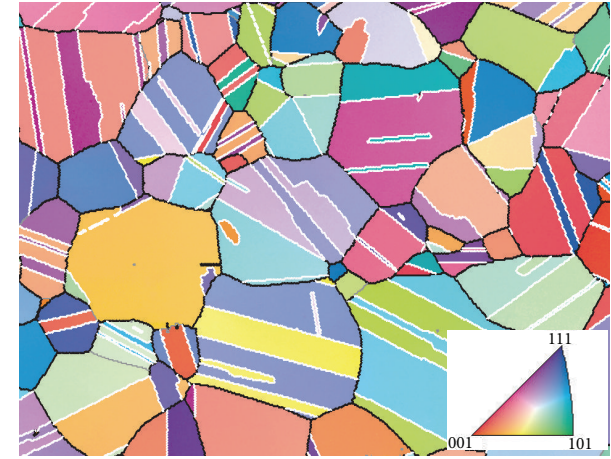

(b)

FIgURE 9: Microstructure of 316LN steels with different N contents heat treated at $1473 \mathrm{~K}$ for $60 \mathrm{~min}$ : (a) $08 \mathrm{~N}$; (b) $17 \mathrm{~N}$.

curves (Figure 1). Furthermore, the critical strain for the initiation of DRX in Section 3.3 is based on the flow data, which does not concern the possible flow instability. Therefore, the larger unstable region in $17 \mathrm{~N}$ might be the reason why the critical strain points are much dispersed (Figure 5).

3.5. Deformed Microstructure. Figure 7 shows the microstructure of 316LN steels with different $\mathrm{N}$ contents deformed at $1273 \mathrm{~K}$ and $0.1 \mathrm{~s}^{-1}$. It can be seen that a small amount of DRX grains forms around parent grains in Figure $7(\mathrm{a})$, that is, necklace structure [23]. In Figure 7(b), the DRX extent is larger than that in Figure 7(a). Obviously, $N$ promotes the DRX process. This is consistent with the result in Figure 5.

Figure 8 shows the microstructure of 316LN steel with different $\mathrm{N}$ contents deformed at $1473 \mathrm{~K}$ and $0.001 \mathrm{~s}^{-1}$. Full DRX has occurred under both $\mathrm{N}$ content conditions. It is very interesting to note that the DRX grain size is finer in Figure 8(b) than that in Figure 8(a). That is to say, DRX grain size decreases with increasing $\mathrm{N}$ content.

3.6. Grain Growth. Figure 9 shows the microstructure of $316 \mathrm{LN}$ steel with different $\mathrm{N}$ contents heat treated at $1473 \mathrm{~K}$ 


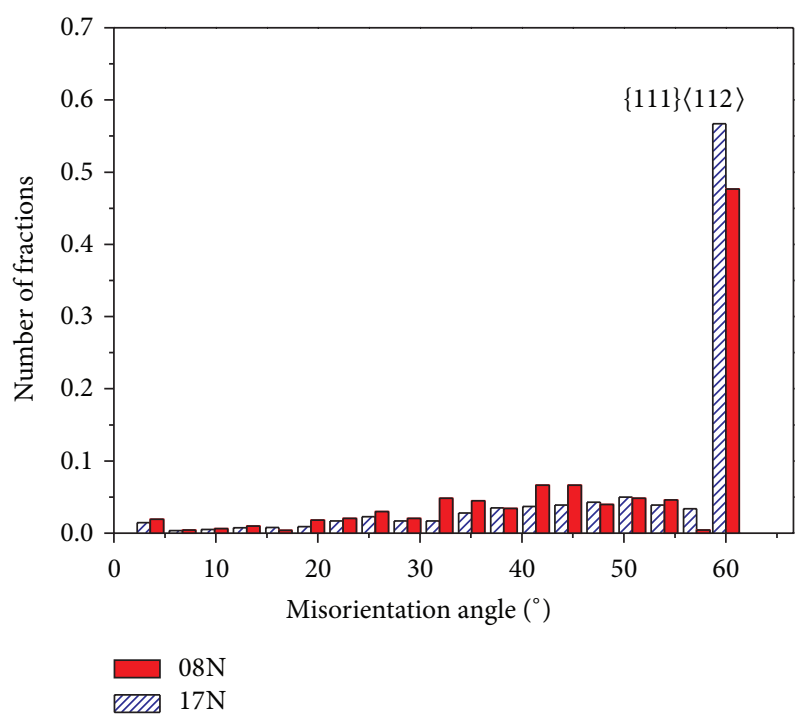

FIGURE 10: Distributions of misorientation angle in the matrix after holding at $1473 \mathrm{~K}$ for $60 \mathrm{~min}$.

for $60 \mathrm{~min}$. It can be seen that the grain size in Figure 9(a) $(08 \mathrm{~N})$ is larger than that in Figure $9(\mathrm{~b})(17 \mathrm{~N})$. A lot of twin boundaries exist in both specimens. It seems that the specimen with high $\mathrm{N}$ content contains more twin boundaries.

The misorientation angle distributions of these two specimens are shown in Figure 10. Obviously, the fractions of twin boundary in both specimen are beyond 0.4 . It is notable that the twin boundary fraction increases with increasing $\mathrm{N}$ content. In grain boundary engineering, it is believed that these special boundaries can dramatically improve the chemical and mechanical properties of metallic materials. Therefore, one can infer that the effect of $\mathrm{N}$ content on twin boundary fraction is of practical interest in grain boundary engineering. It should be pointed out that a few of low angle grain boundaries may be induced by specimen preparation in Figure 9.

The grain size of $316 \mathrm{LN}$ steel after heat treatment at $1473 \mathrm{~K}$ for 5-300 min was measured using the liner interception method. The results of the measurements are shown in Figure 11. The initial grain sizes are about $20 \mu \mathrm{m}$ in both types of steel. After holding at $1473 \mathrm{~K}$ for $30 \mathrm{~min}$, their size can reach to about $200 \mu \mathrm{m}$. Obviously, in the whole treatment process, the grain growth rates are higher in $08 \mathrm{~N}$ specimen than in $17 \mathrm{~N}$ steel. In the further work, more quantitative studies will be done. In addition, the effect of $\mathrm{N}$ content on the DRX mechanism, flow instability mechanism, and hot ductility will also be investigated in the future.

\section{Conclusions}

(1) Under most conditions, the flow stress of $17 \mathrm{~N}$ was higher than that of $08 \mathrm{~N}$. This difference became more pronounced at lower temperatures.

(2) The strain rate sensitivity was increased with increasing temperature for both $08 \mathrm{~N}$ and $17 \mathrm{~N}$. The higher the $\mathrm{N}$ content, the higher the strain rate sensitivity.

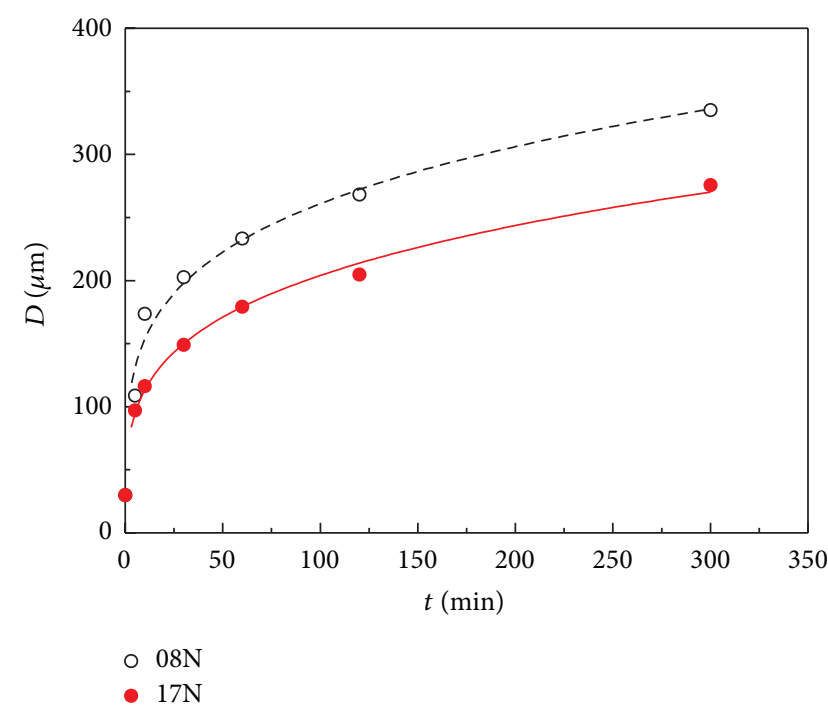

FIGURE 11: Effect of $\mathrm{N}$ content on grain growth rate.

(3) Hot deformation activation energy increased from $487 \mathrm{~kJ} / \mathrm{mol}$ to $549 \mathrm{~kJ} / \mathrm{mol}$ as $\mathrm{N}$ concentration was increased from $0.08 \%$ to $0.17 \%$.

(4) The critical strain for initiation of DRX was lowered with increasing $\mathrm{N}$ content. $\mathrm{N}$ increased the power dissipation ratio and the unstable region.

(5) N promoted DRX kinetic and decreased DRX grain size.

(6) $\mathrm{N}$ restrained the grain growth rate during heat treatment. $\mathrm{N}$ favored twin boundary formation.

\section{Conflict of Interests}

The authors declare that there is no conflict of interests regarding the publication of this paper.

\section{Acknowledgments}

The project is supported by the Natural Science FoundationSteel and Iron Foundation of Hebei Province (E2013203110) and the Foundation for Young Scholars in Yanshan University (14LGA004).

\section{References}

[1] N. S. Bharasi, K. Thyagarajan, H. Shaikh et al., "Effect of flowing sodium on corrosion and tensile properties of AISI type 316LN stainless steel at $823 \mathrm{~K}$," Journal of Nuclear Materials, vol. 377, no. 2, pp. 378-384, 2008.

[2] S. J. Pawel, "Assessment of cavitation-erosion resistance of 316LN stainless steel in mercury as a function of surface treatment," Journal of Nuclear Materials, vol. 343, no. 1-3, pp. 101-115, 2005.

[3] A. Poonguzhali, M. G. Pujar, and U. K. Mudali, "Effect of nitrogen and sensitization on the microstructure and pitting corrosion behavior of AISI type 316LN stainless steels," Journal of Materials Engineering and Performance, vol. 22, no. 4, pp. 11701178, 2013. 
[4] J.-B. Lee and S.-I. Yoon, "Effect of nitrogen alloying on the semiconducting properties of passive films and metastable pitting susceptibility of 316L and 316LN stainless steels," Materials Chemistry and Physics, vol. 122, no. 1, pp. 194-199, 2010.

[5] M. D. Mathew, K. Laha, and V. Ganesan, "Improving creep strength of 316L stainless steel by alloying with nitrogen," Materials Science and Engineering A, vol. 535, pp. 76-83, 2012.

[6] V. Ganesan, J. Ganesh Kumar, K. Laha, and M. Mathew, "Notch creep rupture strength of 316LN SS and its variation with nitrogen content," Nuclear Engineering and Design, vol. 254, pp. 179-184, 2013.

[7] M. D. Mathew and D. Vijayanand, "Impression creep behavior of 316LN stainless steel," Journal of Materials Engineering and Performance, vol. 22, no. 2, pp. 492-497, 2013.

[8] Naveena, V. D. Vijayanand, V. Ganesan, K. Laha, and M. D. Mathew, "Evaluation of the effect of nitrogen on creep properties of 316LN stainless steel from impression creep tests," Materials Science and Engineering A, vol. 552, pp. 112-118, 2012.

[9] M. N. Babu, B. S. Dutt, S. Venugopal et al., "Fatigue crack growth behavior of 316LN stainless steel with different nitrogen contents," Procedia Engineering, vol. 55, pp. 718-721, 2013.

[10] W.-Y. Maeng and M.-H. Kim, "Comparative study on the fatigue crack growth behavior of 316L and 316LN stainless steels: effect of microstructure of cyclic plastic strain zone at crack tip," Journal of Nuclear Materials, vol. 282, no. 1, pp. 32-39, 2000.

[11] G. V. P. Reddy, R. Sandhya, M. Valsan, K. B. S. Rao, and S. Sankaran, "Strain controlled fatigue deformation and fracture of nitrogen alloyed 316LN austenitic stainless steel," Transactions of the Indian Institute of Metals, vol. 63, no. 2-3, pp. 505$510,2010$.

[12] D. W. Kim, "Influence of nitrogen-induced grain refinement on mechanical properties of nitrogen alloyed type 316LN stainless steel," Journal of Nuclear Materials, vol. 420, no. 1-3, pp. 473478, 2012.

[13] M. Tendo, Y. Tadokoro, K. Suetsugu, and T. Nakazawa, "Effects of nitrogen, niobium and molybdenum on strengthening of austenitic stainless steel produced by thermo-mechanical control process," ISIJ International, vol. 41, no. 3, pp. 262-267, 2001.

[14] Y.-P. Lang, Y. Zhou, F. Rong, H.-T. Chen, Y.-Q. Weng, and J. Su, "Hot working of high nitrogen austenitic stainless steel," Journal of Iron and Steel Research International, vol. 17, no. 10, pp. 45-49, 2010.

[15] C. M. Hong, J. Shi, L. Y. Sheng, W. C. Cao, W. J. Hui, and H. Dong, "Effects of hot-working parameters on microstructural evolution of high nitrogen austenitic stainless steel," Materials \& Design, vol. 32, no. 7, pp. 3711-3717, 2011.

[16] Z. H. Wang, W. T. Fu, S. H. Sun, H. Li, Z. Q. Lv, and D. L. Zhao, "Mechanical behavior and microstructural change of a high nitrogen crmn austenitic stainless steel during hot deformation," Metallurgical and Materials Transactions A, vol. 41, no. 4, pp. 1025-1032, 2010.

[17] S.-P. Tan, Z.-H. Wang, S.-C. Cheng, Z.-D. Liu, J.-C. Han, and W.T. Fu, "Hot deformation behavior of Super304H austenitic heat resistant steel," International Journal of Minerals, Metallurgy and Materials, vol. 17, no. 2, pp. 167-172, 2010.

[18] K.-D. Woo, S.-W. Kim, C.-H. Yang, T. P. Lou, and Y. Miura, "Effects of grain size on high temperature deformation behavior of $\mathrm{Al}-4 \mathrm{Mg}-0.4 \mathrm{Sc}$ alloy," Materials Letters, vol. 57, no. 13-14, pp. 1903-1909, 2003.
[19] S. F. Medina and C. A. Hernandez, "General expression of the Zener-Hollomon parameter as a function of the chemical composition of low alloy and microalloyed steels," Acta Materialia, vol. 44, no. 1, pp. 137-148, 1996.

[20] E. I. Poliak and J. J. Jonas, "Initiation of dynamic recrystallization in constant strain rate hot deformation," ISIJ International, vol. 43, no. 5, pp. 684-691, 2003.

[21] A. Najafizadeh and J. J. Jonas, "Predicting the critical stress for initiation of dynamic recrystallization," ISIJ International, vol. 46, no. 11, pp. 1679-1684, 2006.

[22] Y. V. R. K. Prasad and S. Sasidhara, Hot Working Guide: A Compendium of Processing Maps, ASM International, Materials Park, Ohio, USA, 1st edition, 1997.

[23] D. Ponge and G. Gottstein, "Necklace formation during dynamic recrystallization: mechanisms and impact on flow behavior," Acta Materialia, vol. 46, no. 1, pp. 69-80, 1998. 

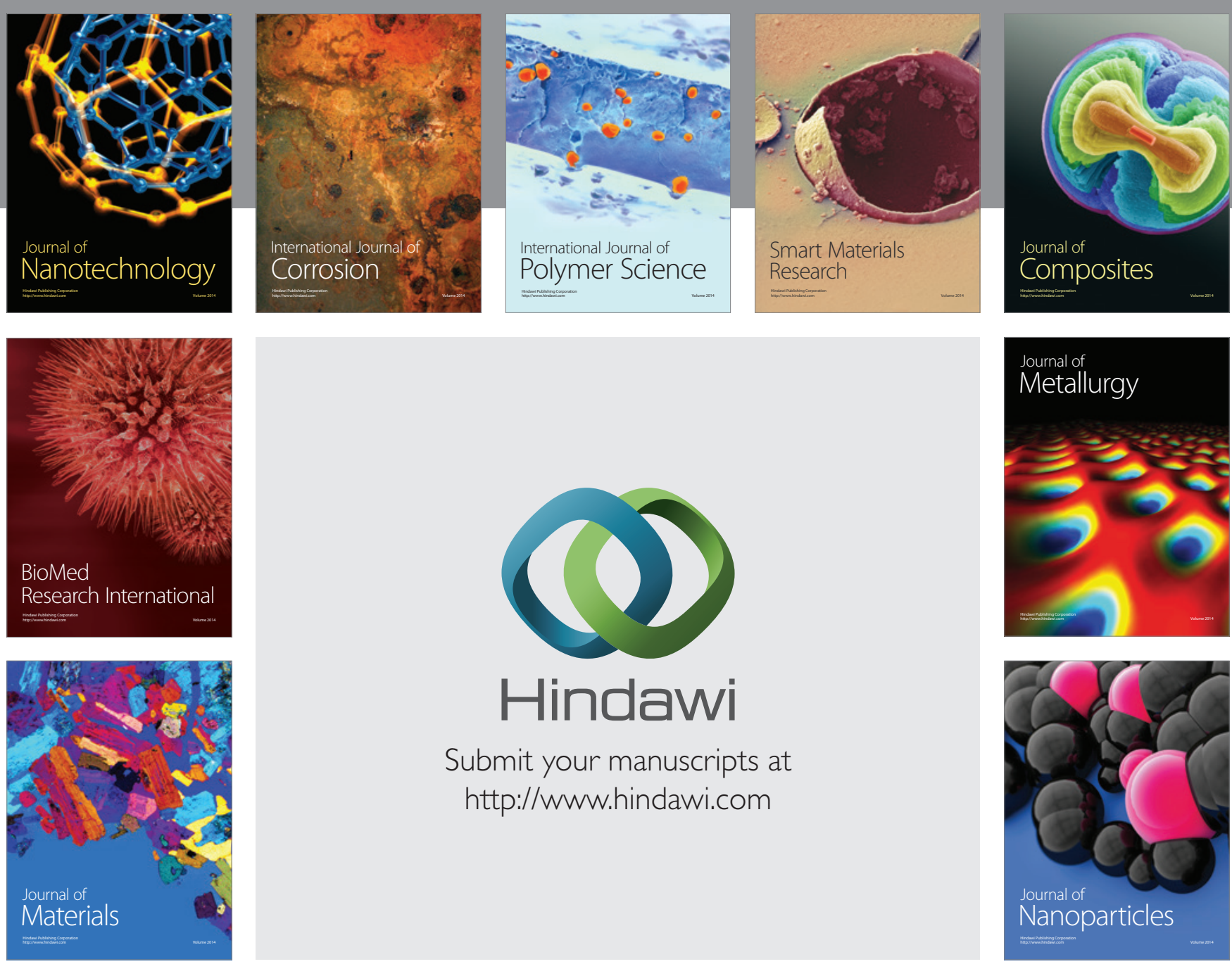

Submit your manuscripts at http://www.hindawi.com
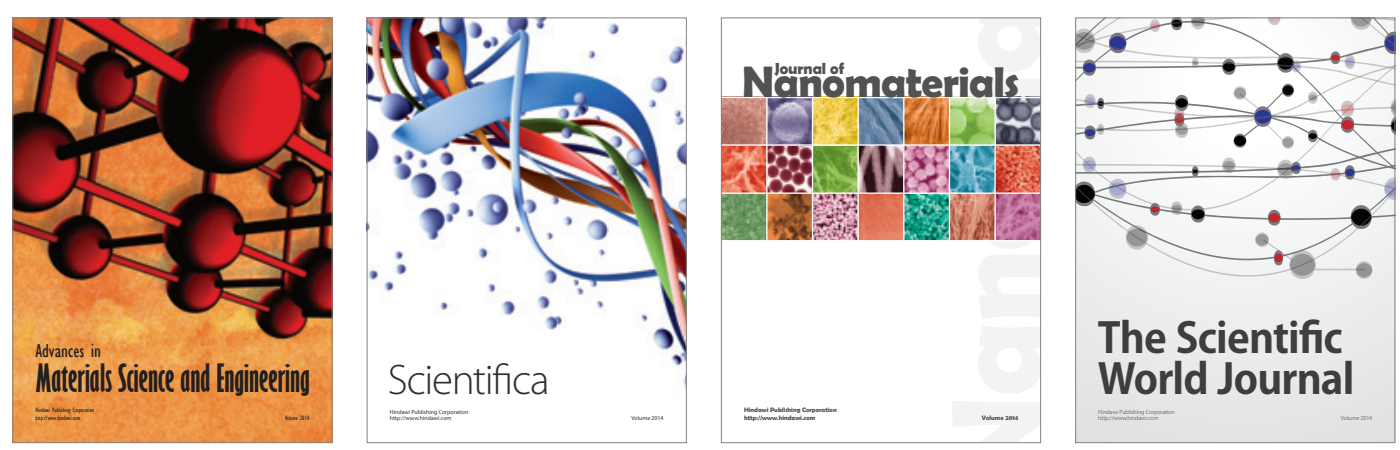

\section{The Scientific World Journal}
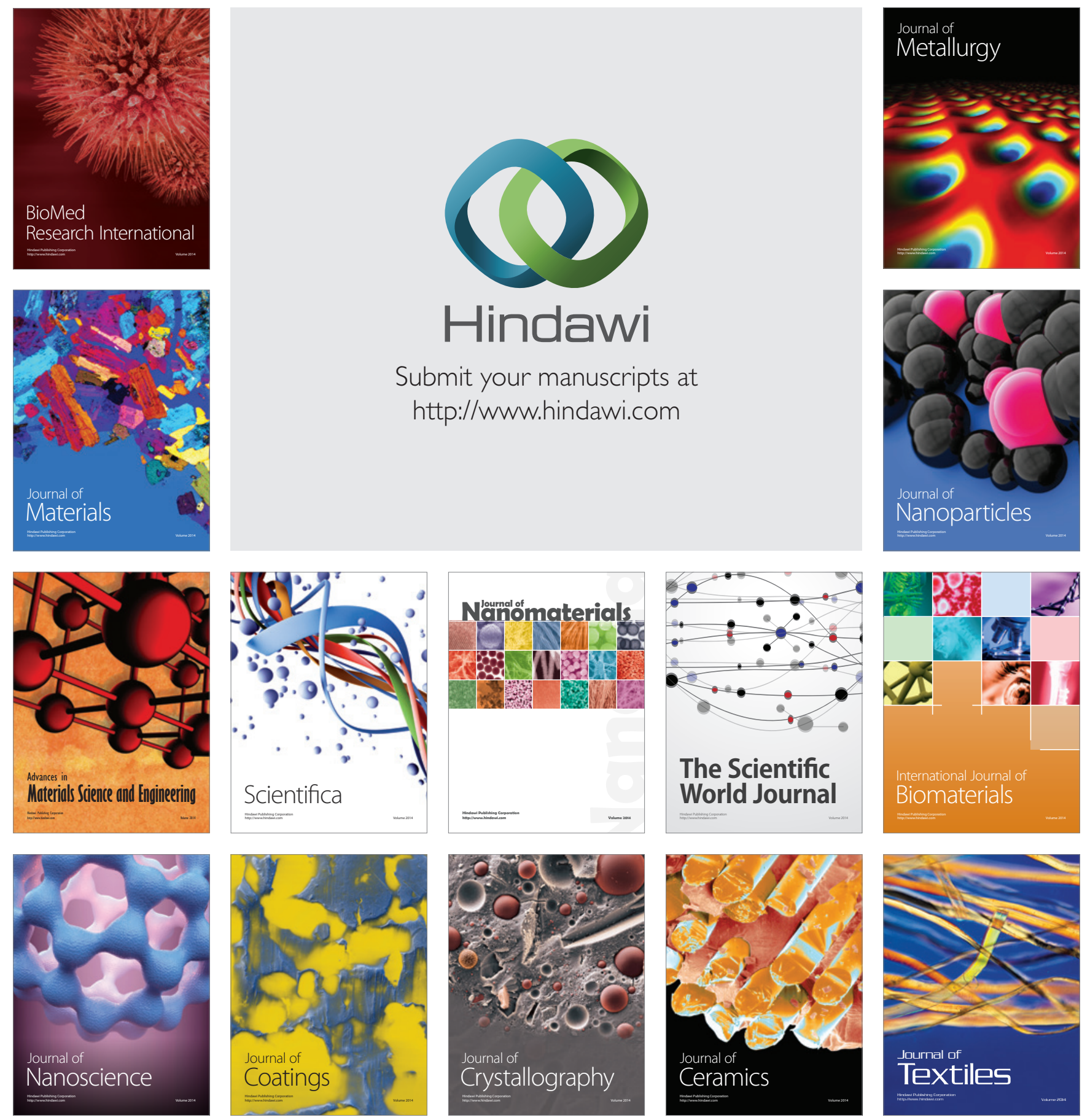